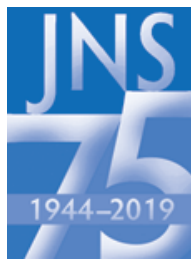

\title{
Global neurosurgery: innovators, strategies, and the way forward
}

\author{
JNSPG 75th Anniversary Invited Review Article
}

Michael M. Haglund, MD, PhD, MACM, ${ }^{1-3}$ and Anthony T. Fuller, MD, MScGH ${ }^{1-3}$

1'Duke University Division of Global Neurosurgery and Neurology; and 'Department of Neurosurgery, Duke University Medical Center; and ${ }^{3}$ Duke University Global Health Institute, Durham, North Carolina

\begin{abstract}
Around the world today, low- and middle-income countries (LMICs) have not benefited from advancements in neurosurgery; most have minimal or even no neurosurgical capacity in their entire country. In this paper, the authors examine in broad strokes the different ways in which individuals, organizations, and universities engage in global neurosurgery to address the global challenges faced in many LMICs. Key strategies include surgical camps, educational programs, training programs, health system strengthening projects, health policy changes/development, and advocacy. Global neurosurgery has begun coalescing with large strides taken to develop a coherent voice for this work. This large-scale collaboration via multilateral, multinational engagement is the only true solution to the issues we face in global neurosurgery. Key players have begun to come together toward this ultimate solution, and the future of global neurosurgery is bright. https://thejns.org/doi/abs/10.3171/2019.4.JNS181747
\end{abstract}

KEYWORDS global neurosurgery; health system strengthening; global surgery

$\mathrm{M}$ ODERN neurosurgery has catapulted into one of the most complex specialties in healthcare due to the individual and collective action of neurosurgeons across the globe. Giant leaps in patient care have transformed the field, turning once inoperable cases into standard practice. Countless lives have been changed by this progress, but its impact has been disproportionate. Around the world today, low- and middle-income countries (LMICs) have not benefited from advancements in neurosurgery; most have minimal or even no neurosurgical capacity in their entire country. ${ }^{15,17}$

Equitable distribution of healthcare advancements and overall improvement of quality healthcare has been and continues to be a major global challenge. ${ }^{25,57}$ Global health as an area of intellectual engagement began, in part, as a response to solving this problem. Most of the early work in global health focused on infectious disease, and only within the last 10-15 years have global health efforts shifted to be fully inclusive of surgery, moving global surgery from its position as the "neglected stepchild."18 The landmark work pushing global surgery into the international discussion came in 2015 from the Lancet Commission on Global Surgery. ${ }^{39-41,45}$ In their seminal article, they explained the dire need for global surgery by exposing the vast inequi- ties present in global access to safe, affordable, and quality surgery, and called for a global response. ${ }^{41}$ Global surgery leaders have responded; projects and interventions have continued to expand and flourish, with many innovative and impactful approaches being developed, piloted, and implemented worldwide.

Global neurosurgery is a niche area within global surgery, and in the broader context of global health exists in relative obscurity. Despite its recent rise in prominence, global neurosurgery has existed for decades with tremendous work being performed worldwide. As is the case with most global surgery efforts, the earliest work in global neurosurgery began as surgical camps to provide free surgical services to those in dire need. ${ }^{13,29}$ Recent strategies have taken a broader approach, focusing on health system strengthening and cost-effectiveness with neurosurgery development as its driving force. ${ }^{26,50}$

As global surgery continues to grow and develop, so does global neurosurgery. In this paper we will examine, in broad strokes, the different ways in which individuals, organizations, and universities engage in global neurosurgery (Fig. 1). We will end with themes and potential strategies for global neurosurgery moving forward. Undoubtedly some programs and activities will be missed in our

ABBREVIATIONS DGNN = Duke Global Neurosurgery and Neurology; FIENS = Foundation for International Education in Neurological Surgery; GNI = Global Neurosurgery Initiative; LMICs = low- and middle-income countries; NGO = nongovernmental organization; PGSSC = Program in Global Surgery and Social Change; WFNS = World Federation of Neurosurgical Societies. 


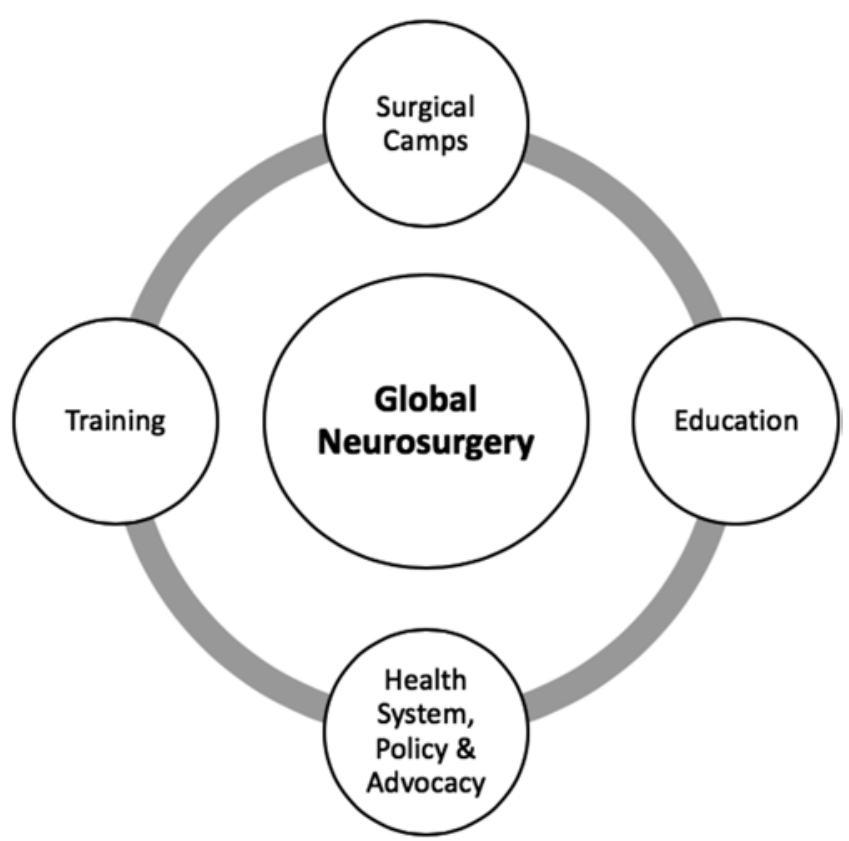

FIG. 1. Representation of different strategies used in global neurosurgery.

effort to describe the extent and reach of this field. Our paper provides examples and is not meant to lessen or not credit the dedicated individuals and organizations who have done, and continue to do, amazing work in global neurosurgery.

\section{Global Neurosurgery Strategies}

Global neurosurgery has been defined as "an area for study, research, practice, and advocacy that places priority on improving health outcomes and achieving health equity for all people worldwide who are affected by neurosurgical conditions or have a need for neurosurgical care."'12,46 Recently, the Global Neurosurgery Initiative (GNI) at the Program in Global Surgery and Social Change (PGSSC) at Harvard University published an article showing that the annual case deficit-which is the number of essential neurosurgery cases needed beyond the current neurosurgical capacity-is nearly 2 million cases in the WHO's African region and 2.5 million in the WHO's Southeast Asian region. ${ }^{15}$ Pairing this with the plethora of other issues surrounding the provision of surgical care in LMICs illustrates a stark global reality. For those who choose the profession of medicine to help those in need, regardless of their geographic location or socioeconomic status, this reality is a strong call to action. This mindset, and for some a calling, is what drives neurosurgeons worldwide to engage in what is now defined as global neurosurgery (Fig. 2).

\section{Surgical Camps (Provide Surgery to Those in Need)}

Millions of individuals are afflicted by conditions that would improve if provided timely neurosurgical care. An immediate pathway to alleviating this suffering is for a neurosurgeon with the skills and time to travel to an area in need and perform as many procedures as possible. We are defining this strategy in global neurosurgery as a surgical camp. At their core, neurosurgery surgical camps provide surgery to those in need, but variations exist in execution.

One of the earliest and still fairly common methods for neurosurgery surgical camps is for a single neurosurgeon (or a small neurosurgery team) to travel, at their own expense, to an LMIC and provide surgical services for some short period of time. Henry Marsh's work in Ukraine that started in 1992 is a perfect example. His book Do No Harm $^{38}$ and a documentary called The English Surgeon ${ }^{58}$ are the best places to find specifics of his work in Ukraine. Marsh's Ukrainian efforts represent the essence of individual surgical camps: 1) exposure to inequities drives action; 2) taking personal time, effort, and finances to travel and perform surgery; 3) repeated trips, usually on an annual basis; and 4) developing a strong partnership with the local neurosurgeon(s) and hospital. A few examples of other efforts include Alessandro Olivi and Ben Carson's trips to Ghana, Nigeria, and Kenya; ${ }^{28}$ Alfredo Quiñones and Michael Lawton's trips to Mexico and the Philippines (https://missionbrain.org/about-us/); Paul Young and Jose Piquer's trips to Kenya and Tanzania; ${ }^{49}$ Peter Nakaji's trips to Tanzania, Peru, Ecuador, and Nicaragua; ${ }^{42}$ Charlie Teo's work in Peru, Indonesia, and Vietnam;36,55 and Robert Dempsey's work in Ecuador and Kenya. ${ }^{47}$ Numerous other neurosurgeons are participating in surgical camps set up individually or through institutional or foundational programs.

Institutional programs, usually at academic centers in high-income countries, have blossomed from individual efforts. What sets institutional programs apart from individual efforts is typically scale and expanded emphasis. The Co-Pilot Project (https://razomforukraine.org/ projects/cpp/) and International Neurosurgical Children's Association (http://www.incachildren.org/team.asp) are two programs that currently work in Ukraine helping to provide neurosurgical care with an added emphasis on education and training of local practitioners. Another example of an institutional program is Project Shunt out of the University of Michigan (https://medicine.umich.edu/ dept/neurosurgery/projectshunt), which has been going to Guatemala since 1997 and exists as a partnership between the Departments of Neurosurgery, Anesthesia, and Operating Rooms. The program from the University of Toronto is one of the larger endeavors, with more than 25 surgical camps to various hospitals in Indonesia, Ethiopia, Kenya, Zambia, Nigeria, Ukraine, Cambodia, and Ghana. ${ }^{2}$

Adding to the diversity are neurosurgical surgical camps sponsored and supported by various nongovernmental organizations (NGOs)/foundations, missionary groups, and corporations. Chaine de l'Espoir (Chain of Hope-Europe; https://www.chainofhopeeurope.eu) is a network of approximately 6 European NGOs that provide surgical care to populations in need across the globe, and some of their work, such as in Cambodia, focuses on neurosurgery patients. World Medical Missions (https:// www.samaritanspurse.org/what-we-do/world-medicalmission-2/), which is part of the larger missionary organization Samaritan's Purse, helps plan and link interested providers with medical and surgical camps around the 


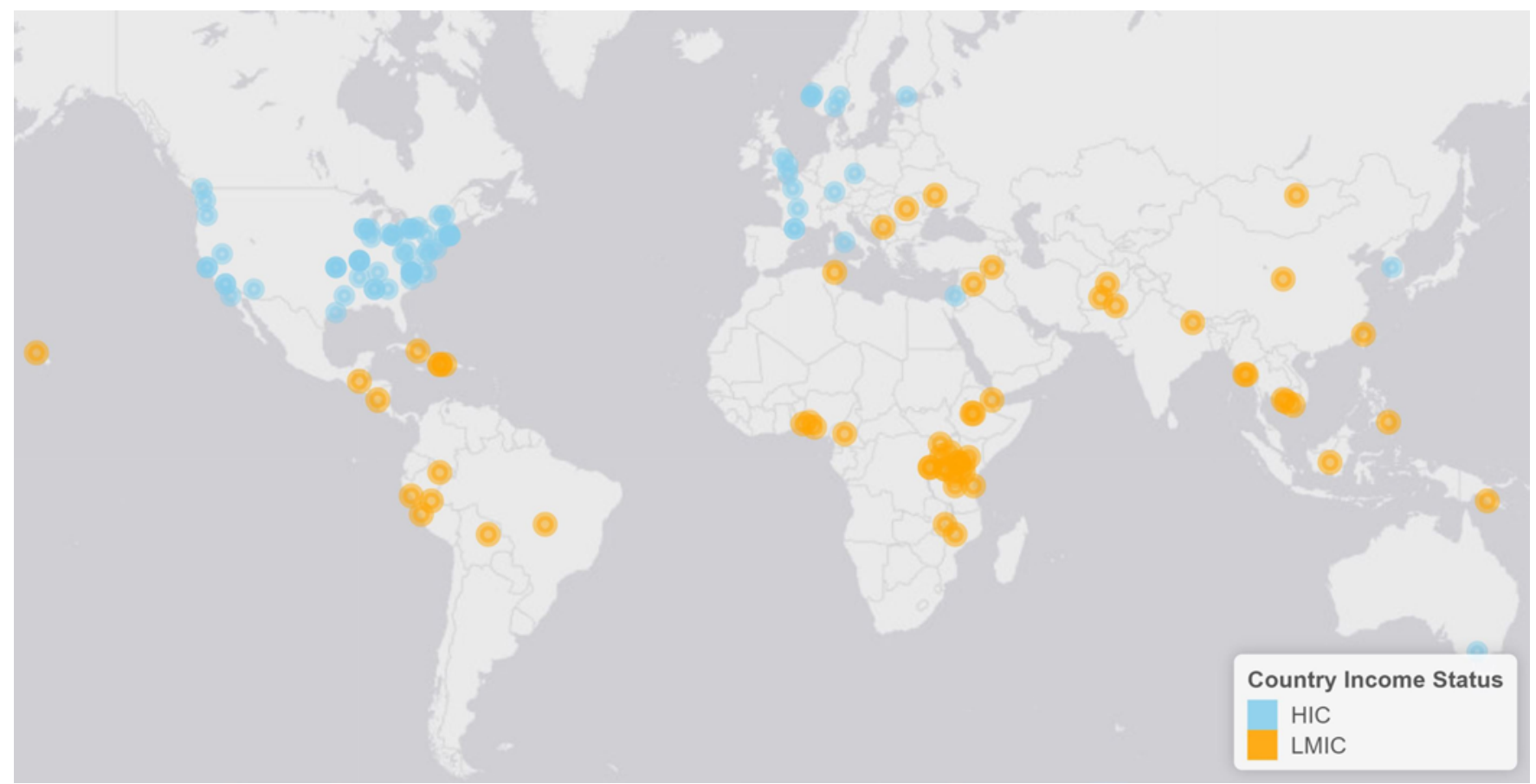

FIG. 2. Distribution of global neurosurgery projects. Blue circles represent the individual, institutional, and foundational programs supported in high-income countries (HICs). Orange circles represent the LMICs these projects operate in. Note: this map is only for projects mentioned/described in this article. Figure is available in color online only.

world. Some of their offerings include surgical camps for neurosurgeons, such as their partnership with Tenwek Hospital in Bomet, Kenya (http://friendsoftenwek.org/ neurosurgery/), which has been developing their neurosurgery capacity in recent years and examining outcomes. ${ }^{32}$ Medical device companies have also pitched in, with some, like NuVasive, developing foundations or corporate responsibility departments that support global neurosurgical work. The NuVasive Spine Foundation has been sponsoring neurosurgical surgical camps for years, and just in 2018 supported nearly 20 trips to all parts of the world (https://nuvasivespinefoundation.org/mission-trips/ partnerships/).

Military interventions are frequently left out of the discussion despite the fact that many military operations have focused on improving neurosurgical care. For the ones that are publicized, these missions start as a way to provide care for injured troops with head injuries. ${ }^{60}$ These efforts then expand to include the local population out of necessity and as a way to give back to the local community. Examples include neurosurgery capacity development during military operations in Iraq and Afghanistan. ${ }^{4,5,11,30}$ There are likely many more of these efforts that do not make it into the public sphere of academic knowledge.

\section{Education (Improve Care Provision)}

Sustainability is a common theme cited as an ethical dilemma for neurosurgery and surgical camps. ${ }^{43,59}$ Many, if not all, of the surgical camps listed above have responded to this dilemma by expanding their efforts to include education and training of local providers. Education is seen as a central tenet for developing long-term, sustain- able solutions to the issues faced in global neurosurgery. In defining this strategy of global neurosurgery engagement, we must differentiate education from formal training in neurosurgery. Education in this context is defined by interventions that focus on skills transfer, teaching medical students/residents/neurosurgeons about specific conditions by giving lectures, and providing educational materials such as books, pamphlets, and videos. Global neurosurgery education programs seek to improve the quality of care that is provided in the country through sharing and improving knowledge. This is distinct from training, which is a formalized process meant to increase the number of neurosurgeons or neurosurgery-capable professionals in the country.

A common scenario faced in global neurosurgery is a hospital that has one neurosurgeon operating in less than ideal conditions, usually in an operating room shared with other specialties. The neurosurgeon likely completed their formal training outside of their home country and choose to return..$^{27,51}$ In this setting, education becomes important for a variety of reasons. First, many of the LMIC neurosurgeons have been operating below their level of training due to resource limitations. This means that even formally trained neurosurgeons in LMICs require some level of education and skills transfer when global neurosurgery efforts bring modern equipment that they have not used in years, or ever. ${ }^{31,48}$ Second, education of the next generation of interested students becomes exceedingly challenging when you are the only neurosurgeon in your district, region, or country. Global neurosurgery programs allow for interested students to learn and become interested in neurosurgery, and many trips have lecture series embedded that discuss common neurosurgical conditions and man- 
agement. An example of this type of program is the Weill Cornell Medicine Neurosurgery Mission in Tanzania, founded in 2008 by Roger Härtl, which has added training components to their trips in addition to setting up a fellowship cosponsored by Fundación NED (Neurocirugia Educacion y DeSarrollo; https://nedfoundation.wordpress. com/about-2/), a nonprofit organization based in Valencia, Spain, and supported by Paul Young, José Piquer, and Mahmood Qureshi. Third, many LMICs have limited access to educational materials like books, operative videos, and other educational supplies, so an important facet of some programs is donating and setting up access to these materials to all interested providers and students. Education of biomedical engineers and technicians is also part of some programs as maintenance of donated equipment and supplies is vital to having an impact beyond the surgical camps. ${ }^{22}$ Lastly, extremely complex cases and "first ever in country" cases are common during surgical camps; thus, education of neurosurgeons through skills transfer during the case is the only way to create competencies so that those procedures can be performed outside of surgical camps. Additionally, due to the need for complex medical management and the short-term nature of many trips, education on postoperative follow-up is imperative for successful neurosurgical outcomes.

\section{Training (Increase the Number of Neurosurgeons)}

Training more neurosurgeons and neurosurgery-capable providers is the only solution for closing the gap in the neurosurgeon-to-population ratio. Global neurosurgery engages in training through the development of visiting residencies or fellowships, development of in-country residency or fellowship programs, and formalized neurosurgical skills transfer to other healthcare professionals to develop their ability to care for neurosurgery patients.

The University of Toronto has been training LMIC neurosurgeons as part of their Neuro-oncology and Skull Base Surgery Fellowship at the Toronto Western Hospital since $2010 .^{2}$ This fellowship is a 1-year program that allows for the visiting trainee to be exposed to and learn the latest techniques and then return to their home country. A similar fellowship in pediatric neurosurgery has been established at the Hospital for Sick Children (https://surgery. utoronto.ca/fellowship-clinical-pediatric-neurosurgery). "Brain drain" (the emigration of highly qualified people) is a common criticism brought against these types of programs, and while evidence implicating any one program is scarce, the phenomenon is undeniably present. ${ }^{52}$

One way to address the concern of brain drain is to develop long-term training programs in the LMIC. An example is the collaboration between Project Medishare and the Global Institute of the University of Miami Miller School of Medicine. They have developed a program in Haiti to train general surgeons to become neurosurgeons.$^{53}$ Other training programs have been developed by a neurosurgeon moving to the LMIC. Benjamin Warf in Mbale, Uganda, and A. Leland Albright in Kijabe, Kenya, are two perfect examples of neurosurgeons who decided to do just that. Benjamin Warf in partnership with CURE International helped develop a pediatric neurosurgery training program in Uganda, which now has visiting train- ees from across Africa. ${ }^{14}$ Warf's work additionally led to advancements in the care of patients with hydrocephalus in LMICs, which are being applied globally. ${ }^{8,33,34,54} \mathrm{~A}$. Leland Albright was able to accomplish a similar feat in Kijabe, Kenya, accompanied by his wife Susan Ferson. They moved to Kijabe, Kenya, in 2010 and helped care for patients while developing a training program for pediatric neurosurgeons (https://kenyainitiative.weebly.com/about. html). ${ }^{24,44}$ Both of these efforts exemplify what can be accomplished in global neurosurgery with motivated global neurosurgeons and outstanding in-country neurosurgeons and partnerships.

The Foundation for International Education in Neurological Surgery (FIENS) has been promoting the training of neurosurgeons on a global scale since 1969. ${ }^{3}$ FIENS has made tremendous impacts in Central America, South America, Asia, and most recently Africa, due to the past leadership of Merwyn Bagan and current leadership of Robert Dempsey. An important distinction of the work FIENS has engaged in has been its emphasis on the development of in-country residencies/fellowships to train neurosurgeons. Providing in-country opportunities for neurosurgery training is a massive step toward decreasing the gap in neurosurgical care and creating a sustainable future for neurosurgery in LMICs. The Neurosurgical Training Program of East Africa led by Moody Qureshi from Kenya and approved through the College of Surgeons of East, Central, and Southern Africa (COSECSA) has developed neurosurgery training programs in Ethiopia, Kenya, Tanzania, and Uganda. ${ }^{6}$ Our group, Duke Global Neurosurgery and Neurology (DGNN), helps support the Uganda program, which started in 2009, and to date we have been able to train 5 Ugandans to become neurosurgeons, graduated the first woman neurosurgeon this past year, and have 6 more residents in the program. ${ }^{27}$ In Ethiopia, the neurosurgery training program has been incredibly successful at increasing the number of neurosurgeons and the number of neurosurgery cases performed and has been supported since 2004 through a partnership between the University of Bergen, Haukeland University Hospital, the Black Lion Specialized Hospital, and a private hospital in Addis Ababa. ${ }^{37}$

Task-shifting or training an entry-level provider to do very specific tasks has been widely used throughout global health, and has advocates within global surgery due to its expediency and implications on cost., ${ }^{9,10,19}$ Faced with a neurosurgeon ratio gap that is nearly impossible to close expeditiously, the length of time it takes to fully train a neurosurgeon, and the increased incidence of traumatic brain injuries requiring care, ${ }^{16}$ global neurosurgery strategies have included task-shifting as a necessary component. Led by Dilan Ellegala, a successful task-shifting model described as "train forward" has had great success in Tanzania through an organization called Madaktari Africa (https://www.madaktari.org) whose mission is to "advance medical expertise and care in sub-Saharan Africa through the training and education of local medical personnel." ${ }^{20}$ While this model may not be applicable in all LMICs, using a "train-the-trainer" model and having neurosurgeons teach general surgeons how to perform basic neurosurgery trauma procedures is a viable solution to not 
only increase capacity but also decentralize neurosurgical care, which is usually localized to major city centers. ${ }^{7,17}$

\section{Health System Strengthening, Health Policy, and Advocacy (Improve the System of Care)}

Expert global opinion is shifting within global health beyond vertical projects, specific to one condition or disease, to horizontal projects, which aim to address the underlying issues within the health system in LMICs. ${ }^{21}$ This change has occurred partly due to the fact that noncommunicable diseases and chronic conditions cannot be solved by the traditional approaches applied to infectious disease. Global neurosurgery work falls within this mindset shift as surgery provision in its best form requires a well-functioning health system. ${ }^{41}$ Within the past 5-10 years more neurosurgery groups are broadening their scope to include health system strengthening projects, examining healthcare policy, and advocating at national and international levels. This strategy of global neurosurgery focuses on the system of care surrounding neurosurgeons and their patients. While there are more programs domestically and abroad, we wanted to highlight two in the US engaging in global neurosurgery at this level: Duke Global Neurosurgery and Neurology (DGNN) (our group) at Duke University, and the Global Neurosurgery Initiative (GNI) at the Program in Global Surgery and Social Change (PGSSC) at Harvard University.

DGNN traces back to 2007, when the first surgical camp to Uganda occurred with a focus on providing neurosurgical care, bringing much-needed equipment, and training the local neurosurgeons and other healthcare providers. ${ }^{26}$ In 2014, DGNN officially became a formal division in the Duke Department of Neurosurgery and its focus expanded to include strengthening health systems. Our approach to strengthening health systems entails looking at the entire healthcare continuum for neurosurgery patients from prehospital care to in-hospital care, and ultimately patients returning to their communities. Using this approach, we have been able to complete epidemiology research to understand the burden of surgery across Uganda ${ }^{56}$ and outcomes research to examine the impact on patients in our partner hospitals, ${ }^{1,23}$ develop interventions for improving transitions of care, and set up databases ${ }^{35}$ and infrastructure for continued research and in the near-future clinical trials in neurosurgery and neurology. Using our published work and internally generated metrics, we have been able to work closely with Ugandan public hospitals to improve the provision of neurosurgery, discuss policy changes with the Ugandan Ministry of Health, and advocate nationally and internationally for health system changes.

The PGSSC is a collaborative effort between the Harvard teaching hospitals, Department of Global Health and Social Medicine at Harvard Medical School, Boston Children's Hospital, and Partners In Health..$^{15}$ PGSSC's primary objective is to advocate for universal access to safe, affordable surgical, obstetric, and anesthesia care when needed. The GNI exists within PGSSC's framework and focuses on research, policy, and advocacy within global neurosurgery. Their research has produced metrics showing the magnitude of the problem we face in global neurosurgery. Ongoing work from GNI includes pediatric neu- rosurgical training in Mbale, Uganda; research examining health policy and economic implications for global neurosurgery; and global surveys examining neurosurgeon perspectives and current capacity in LMICs, which is being conducted in partnership with the World Federation of Neurosurgical Societies (WFNS) and the National Institute for Health Research Global Health Research Group on Neurotrauma.

\section{Way Forward}

Global neurosurgery faces tremendous challenges that no single individual, organization, or university is able to solve. While each of the strategies detailed above pushes us in the right direction, we advocate that for our field to truly make a global impact we must 1) change our scope to focus on the systemic issues within the LMICs, which is best done through the lens of health system strengthening; 2) develop broader data sets leveraging the various successful databases already in existence to create global metrics and to serve as platforms for collaborative research; and 3) collaborate on the global scale by bringing together the expertise from the various entities engaged in global neurosurgery through annual conferences, centralizing where to turn for guidance, and developing a cohesive global strategy.

A health system strengthening approach allows us to work collaboratively and engage in better research and advocacy. Long-lasting neurosurgical advancement in LMICs is impossible without concordant advancements in anesthesiology, nursing, physical therapy, and biomedical engineering, to name a few. Expertise in these other areas allows for cohesive health system planning that is not myopic for any single specialty. At the health system level, partnerships allow for the development of projects and research that have the potential to sway national and international policy. Single-ward, single-site projects are less likely to change national policy. Lastly, this level of focus provides an ability to advocate on the individual level, allowing for immediate change, while advocating at the systemic level, which has the ability to create long-term change.

Big data, predictive modeling, and machine learning are all tools that have the capability to generate change on a global scale. Within global neurosurgery there is a lack of large data sets, especially data sets with multiple LMIC data included. This lack of data decreases our ability to truly understand the scope of the problem, model economic impact of different strategies, and understand the true impact of the strategies listed above. Some groups have been able to produce data on outcomes, economic impact, and burden, but at the moment data sets are isolated and have not been merged. Large data sets from multiple countries allow us to develop broader research questions and test their impact, which is a major deficit in global neurosurgery at the moment.

Global collaboration, beyond sharing and merging data, is the only way to effectively work in this field as our challenges are too daunting to handle alone. Surgical camps would be improved if groups working in the same country knew about each other's activities. This could cut down on overall costs and duplication of efforts, and allow for a broader national strategy to be developed. Educa- 
tion programs would be improved as materials and models that have worked could be used in other settings, and a global repository for educational materials for LMICs could be developed, much like the goal of the nationwide US Neurosurgery Matrix Program and teaching programs emanating from Canada. ${ }^{2}$ Training programs would be improved by shifting financial implications, broadening the clinical exposure experiences, and allowing better advocacy at the governmental level for trainees to enter the public healthcare system.

Fortunately, there have been many recent efforts to spark the global collaboration within global neurosurgery. Global neurosurgery has taken the spotlight at many recent neurosurgery conferences such as the WFNS and AANS. The Bogota Declaration was developed which outlines the field and its purpose within global surgery (https://globalneurosurgery.org/bogota-declaration/). Having neurosurgeons in positions of leadership at the WHO, such as Walter Johnson, MD, allows for a broader impact and understanding of the great need for neurosurgical care in LMICs. Additionally, there is the Consensus Statement on Global Neurosurgery (https://globalneurosurgery.org/ consensus-statement/), which provides an analysis of what the field should be doing and provides recommendations on priorities. These efforts are clear steps toward global collaboration; with continued support we will realize our goal to work together to solve the challenges facing our field.

\section{Conclusions}

Global neurosurgery is a burgeoning field in which its key players strive to make a difference through surgical camps, educational programs, training programs, health system strengthening projects, health policy changes/development, and advocacy. In recent years, the field has begun coalescing with large strides taken to develop a coherent voice for this work. This large-scale collaboration via multilateral, multinational engagement is the only true solution to the issues we face in global neurosurgery. Key players have begun to come together toward this ultimate solution, and the future of global neurosurgery is bright.

\section{References}

1. Abdelgadir J, Punchak M, Smith ER, Tarnasky A, Muhindo A, Nickenig Vissoci JR, et al: Pediatric traumatic brain injury at Mbarara Regional Referral Hospital, Uganda. J Clin Neurosci 47:79-83, 2018

2. Almeida JP, Velásquez C, Karekezi C, Marigil M, Hodaie M, Rutka JT, et al: Global neurosurgery: models for international surgical education and collaboration at one university. Neurosurg Focus 45(4):E5, 2018

3. Bagan M: The Foundation for International Education in Neurological Surgery. World Neurosurg 73:289, 2010

4. Bell RS, Mossop CM, Dirks MS, Stephens FL, Mulligan L, Ecker R, et al: Early decompressive craniectomy for severe penetrating and closed head injury during wartime. Neurosurg Focus 28(5):E1, 2010

5. Brisebois RJ, Tien HC: Surgical experience at the Canadianled role 3 multinational medical unit in Kandahar, Afghanistan. J Trauma 71 (5 Suppl 1):S397-S400, 2011

6. Budohoski KP, Ngerageza JG, Austard B, Fuller A, Galler R, Haglund M, et al: Neurosurgery in East Africa: innovations. World Neurosurg 113:436-452, 2018
7. Burton A: Training non-physicians as neurosurgeons in subSaharan Africa. Lancet Neurol 16:684-685, 2017

8. Cairo SB, Agyei J, Nyavandu K, Rothstein DH, Kalisya LM: Neurosurgical management of hydrocephalus by a general surgeon in an extremely low resource setting: initial experience in North Kivu province of Eastern Democratic Republic of Congo. Pediatr Surg Int 34:467-473, 2018

9. Chao TE, Sharma K, Mandigo M, Hagander L, Resch SC, Weiser TG, et al: Cost-effectiveness of surgery and its policy implications for global health: a systematic review and analysis. Lancet Glob Health 2:e334-e345, 2014

10. Chu K, Rosseel P, Gielis P, Ford N: Surgical task shifting in Sub-Saharan Africa. PLoS Med 6:e1000078, 2009

11. Dagain A, Aoun O, Bordes J, Roqueplo C, Joubert C, Esnault $\mathrm{P}$, et al: Management of war-related ballistic craniocerebral injuries in a French role 3 hospital during the Afghan campaign. World Neurosurg 102:6-12, 2017

12. Dare AJ, Grimes CE, Gillies R, Greenberg SL, Hagander L, Meara JG, et al: Global surgery: defining an emerging global health field. Lancet 384:2245-2247, 2014

13. Dempsey RJ, Nakaji P: Foundation for International Education in Neurological Surgery (FIENS) Global Health and Neurosurgical Volunteerism. Neurosurgery 73:1070-1071, 2013

14. Dewan MC, Onen J, Bow H, Ssenyonga P, Howard C, Warf BC: Subspecialty pediatric neurosurgery training: a skillbased training model for neurosurgeons in low-resourced health systems. Neurosurg Focus 45(4):E2, 2018

15. Dewan MC, Rattani A, Fieggen G, Arraez MA, Servadei F, Boop FA, et al: Global neurosurgery: the current capacity and deficit in the provision of essential neurosurgical care. Executive Summary of the Global Neurosurgery Initiative at the Program in Global Surgery and Social Change. J Neurosurg 130:1039-1408, 2019

16. Dewan MC, Rattani A, Gupta S, Baticulon RE, Hung YC, Punchak M, et al: Estimating the global incidence of traumatic brain injury. J Neurosurg 130:1080-1097, 2019

17. El Khamlichi A: African neurosurgery: current situation, priorities, and needs. Neurosurgery 48:1344-1347, 2001

18. Farmer PE, Kim JY: Surgery and global health: a view from beyond the OR. World J Surg 32:533-536, 2008

19. Federspiel F, Mukhopadhyay S, Milsom P, Scott JW, Riesel JN, Meara JG: Global surgical and anaesthetic task shifting: a systematic literature review and survey. Lancet 385 (Suppl 2):S46, 2015

20. Forrester JD: Unlikely surgeons. Health Aff (Millwood) 36:2026-2027, 2017

21. Frenk J: The global health system: strengthening national health systems as the next step for global progress. PLoS Med 7:e1000089, 2010

22. Fuller A, Tran T, Muhumuza M, Haglund MM: Building neurosurgical capacity in low and middle income countries. eNeurologicalSci 3:1-6, 2015

23. Fuller AT, Haglund MM, Lim S, Mukasa J, Muhumuza M, Kiryabwire J, et al: Pediatric neurosurgical outcomes following a neurosurgery health system intervention at Mulago National Referral Hospital in Uganda. World Neurosurg 95:309-314, 2016

24. Githuku JN, Azofeifa A, Valencia D, Ao T, Hamner H, Amwayi S, et al: Assessing the prevalence of spina bifida and encephalocele in a Kenyan hospital from 2005-2010: implications for a neural tube defects surveillance system. Pan Afr Med J 18:60, 2014

25. Gupta V, Katz R, Swaminathan S: Reimagining development assistance for health. N Engl J Med 379:1891-1893, 2018

26. Haglund MM, Kiryabwire J, Parker S, Zomorodi A, MacLeod D, Schroeder R, et al: Surgical capacity building in Uganda through twinning, technology, and training camps. World J Surg 35:1175-1182, 2011

27. Haglund MM, Warf B, Fuller A, Freischlag K, Muhumuza 
M, Ssenyonjo H, et al: Past, present, and future of neurosurgery in Uganda. Neurosurgery 80:656-661, 2017

28. Johns Hopkins Medicine: Mission to Africa. NeuroNow. June 1, 2011 (https://www.hopkinsmedicine.org/news/ publications/neuronow/neuronow_spring_2011/mission_to_ africa) [Accessed June 24, 2019]

29. Johnson WD: Surgery as a global health issue. Surg Neurol Int 4:47, 2013

30. Joubert C, Dulou R, Delmas JM, Desse N, Fouet M, Dagain A: Military neurosurgery in operation: experience in the French role-3 medical treatment facility of Kabul. Acta Neurochir (Wien) 158:1453-1463, 2016

31. Kahamba JF, Assey AB, Dempsey RJ, Qureshi MM, Härtl R: The second African Federation of Neurological Surgeons course in the East, Central, and Southern Africa region held in Dar es Salaam, Tanzania, January 2011. World Neurosurg 80:255-259, 2013

32. Kanyi JK, Ogada TV, Oloo MJ, Parker RK: Burr-hole craniostomy for chronic subdural hematomas by general surgeons in rural Kenya. World J Surg 42:40-45, 2018

33. Kulkarni AV, Riva-Cambrin J, Browd SR, Drake JM, Holubkov R, Kestle JR, et al: Endoscopic third ventriculostomy and choroid plexus cauterization in infants with hydrocephalus: a retrospective Hydrocephalus Clinical Research Network study. J Neurosurg Pediatr 14:224-229, 2014

34. Kulkarni AV, Schiff SJ, Mbabazi-Kabachelor E, Mugamba J, Ssenyonga P, Donnelly R, et al: Endoscopic treatment versus shunting for infant hydrocephalus in Uganda. N Engl J Med 377:2456-2464, 2017

35. Kuo BJ, Vaca SD, Vissoci JRN, Staton CA, Xu L, Muhumuza $\mathrm{M}$, et al: A prospective neurosurgical registry evaluating the clinical care of traumatic brain injury patients presenting to Mulago National Referral Hospital in Uganda. PLoS One 12:e0182285, 2017

36. Lee VJ, Low E, Ng YY, Teo C: Disaster relief and initial response to the earthquake and tsunami in Meulaboh, Indonesia. Ann Acad Med Singapore 34:586-590, 2005

37. Lund-Johansen M, Dahl JW, Eilertsen GM, Wester K: Establishment of neurosurgery training in Ethiopia. Tidsskr Nor Laegeforen 137:1344-1346, 2017

38. Marsh H: Do No Harm: Stories of Life, Death and Brain Surgery. London: Weidenfeld \& Nicolson, 2014

39. Meara JG, Greenberg SL: Global Surgery 2030: an introduction. Bull Am Coll Surg 100:10-11, 2015

40. Meara JG, Leather AJ, Hagander L, Alkire BC, Alonso N, Ameh EA, et al: Global Surgery 2030: Evidence and solutions for achieving health, welfare, and economic development. Surgery 158:3-6, 2015

41. Meara JG, Leather AJ, Hagander L, Alkire BC, Alonso N, Ameh EA, et al: Global Surgery 2030: Evidence and solutions for achieving health, welfare, and economic development. Lancet 386:569-624, 2015

42. Meeusen AJ: Successful AVM surgery in Nicaragua preserves child's life. Barrow Beyond Borders. June 11, 2013 (http://barrowbeyondborders.weebly.com/news/successfulavm-surgery-in-nicaragua-preserves-childs-life) [Accessed June 24, 2019]

43. Melby MK, Loh LC, Evert J, Prater C, Lin H, Khan OA: Beyond medical "missions" to impact-driven short-term experiences in global health (STEGHs): ethical principles to optimize community benefit and learner experience. Acad Med 91:633-638, 2016

44. Munyi N, Poenaru D, Bransford R, Albright L: Encephalocele-a single institution African experience. East Afr Med J 86:51-54, 2009

45. Ng-Kamstra JS, Greenberg SLM, Abdullah F, Amado V, Anderson GA, Cossa M, et al: Global Surgery 2030: a roadmap for high income country actors. BMJ Glob Health 1:e000011, 2016
46. Park KB, Johnson WD, Dempsey RJ: Global neurosurgery: the unmet need. World Neurosurg 88:32-35, 2016

47. Piquer J, Qureshi MM, Young PH, Dempsey RJ: Neurosurgery Education and Development program to treat hydrocephalus and to develop neurosurgery in Africa using mobile neuroendoscopic training. J Neurosurg Pediatr 15:552-559, 2015

48. Project Hope: Improving neurosurgery capacity in Tanzania. Project Hope. March 18, 2014 (https://www.projecthope.org/ improving-surgical-capacity-in-tanzania/06/2014/) [Accessed June 24, 2019]

49. Qureshi MM, Oluoch-Olunya D: History of neurosurgery in Kenya, East Africa. World Neurosurg 73:261-263, 2010

50. Ravindra VM, Kraus KL, Riva-Cambrin JK, Kestle JR: The need for cost-effective neurosurgical innovation - a Global Surgery Initiative. World Neurosurg 84:1458-1461, 2015

51. Sader E, Yee P, Hodaie M: Barriers to neurosurgical training in Sub-Saharan Africa: the need for a phased approach to global surgery efforts to improve neurosurgical care. World Neurosurg 98:397-402, 2017

52. Santos MM, Qureshi MM, Budohoski KP, Mangat HS, Ngerageza JG, Schöller K, et al: The growth of neurosurgery in East Africa: challenges. World Neurosurg 113:425-435, 2018

53. Shah AH, Barthélemy E, Lafortune Y, Gernsback J, Henry A, Green B, et al: Bridging the gap: creating a self-sustaining neurosurgical residency program in Haiti. Neurosurg Focus 45(4):E4, 2018

54. Stone SS, Warf BC: Combined endoscopic third ventriculostomy and choroid plexus cauterization as primary treatment for infant hydrocephalus: a prospective North American series. J Neurosurg Pediatr 14:439-446, 2014

55. Tamburrini G, Di Rocco F: Editorial. Childs Nerv Syst 28:1293-1294, 2012

56. Tran TM, Fuller AT, Butler EK, Makumbi F, Luboga S, Muhumuza C, et al: Burden of surgical conditions in Uganda: a cross-sectional nationwide household survey. Ann Surg 266:389-399, 2017

57. Varmus H, Klausner R, Zerhouni E, Acharya T, Daar AS, Singer PA: Public health. Grand challenges in global health. Science 302:398-399, 2003

58. Volpe RL: The English Surgeon. 2008. Produced and directed by Geoffrey Smith. Eyeline Films and Bungalow Town Productions. English and Ukrainian, with English subtitles. 1 hour 33 minutes. http://www.theenglishsurgeon.com. J Bioeth Inq 7:261-262, 2010

59. Wall AE: Ethics in global surgery. World J Surg 38:15741580, 2014

60. Wojcik BE, Stein CR, Bagg K, Humphrey RJ, Orosco J: Traumatic brain injury hospitalizations of U.S. army soldiers deployed to Afghanistan and Iraq. Am J Prev Med 38 (1 Suppl):S108-S116, 2010

\section{Disclosures}

Dr. Haglund reports receiving clinical or research support from NuVasive, UCB Pharma, and LifeNet.

\section{Author Contributions}

Conception and design: both authors. Acquisition of data: both authors. Drafting the article: both authors. Critically revising the article: both authors. Reviewed submitted version of manuscript: both authors. Approved the final version of the manuscript on behalf of both authors: Haglund. Administrative/technical/material support: Haglund.

\section{Correspondence}

Michael M. Haglund: Duke University, Durham, NC. michael. haglund@dm.duke.edu. 